Antimonide-Based Approaches for Long-Wavelength VCSELs<smiles>CC(C)CCCC(=O)NC(=O)O</smiles>

John F. Klem, Olga Blum, and Kevin Lear*

Sandia National Laboratories

P. O. Box 5800 MS 0603

Albuquerque, NM 87185

tel: (505) 845-8225 fax: (505) 844-8985 e-mail: jklem@sandia.gov

*MicroOptical Devices

PGCEVIS

AUG 101838

OSTI

Mixed arsenide/antimonide materials have unique properties which make them potentially valuable for use in VCSELs operating at wavelengths longer than $1 \mu \mathrm{m}$. We present our progress in applying these materials to VCSEL designs for $1-1.55 \mu \mathrm{m}$. 


\section{DISCLAIMER}

This report was prepared as an account of work sponsored by an agency of the United States Government. Neither the United States Government nor any agency thereof, nor any of their employees, makes any warranty, express or implied, or assumes any legal liability or responsibility for the accuracy, completeness, or usefulness of any information, apparatus, product, or process disclosed, or represents that its use would not infringe privately owned rights. Reference herein to any specific commercial product, process, or service by trade name, trademark, manufacturer, or otherwise does not necessarily constitute or imply its endorsement, recommendation, or favoring by the United States Government or any agency thereof. The views and opinions of authors expressed herein do not necessarily state or reflect those of the United States Governmeat or any agency thereof. 


\section{DISCLAIMER}

Portions of this document may be illegible in electronic image products. Images are produced from the best available original document. 


\title{
Antimonide-Based Approaches for Long-Wavelength VCSELs
}

\author{
John F. Klem, Olga Blum, and Kevin Lear* \\ Sandia National Laboratories \\ P. O. Box 5800 \\ Albuquerque, NM 87185 \\ *MicroOptical Devices \\ Albuquerque, NM
}

Vertical-cavity surface-emitting lasers (VCSELs) operating at 1.3 or $1.55 \mu \mathrm{m}$ could be key components in the development of low-cost, high-bandwidth fiber-based optical interconnects and networks. The difficulty in realizing these devices on GaAs substrates lies in the unavailability of active region materials with suitable lattice constants which emit light at these wavelengths, while on InP substrates the lattice-matched InAlGaAsP materials available do not possess sufficient refractive index contrast to achieve highly-reflective distributed Bragg reflector (DBR) mirrors with reasonable mirror thicknesses. To date, 1.3 or $1.55 \mu \mathrm{m}$ devices have been fabricated using wafer fusion bonding, dielectric mirror stacks, or very thick device structures. For several reasons, an all-epitaxial approach is desirable.

Recently, we demonstrated an optically-pumped all-epitaxial $1.56 \mu \mathrm{m}$ VCSEL on an InP substrate which combined a simple InGaAs active region with AlAsSb/AlGaAsSb mirror stacks. ${ }^{1}$ The AlGaAsSb material system is well-suited for fabrication of high-reflectivity DBRs due to a significantly higher refractive index contrast than achievable using InAlGaAsP, particularly at $1.55 \mu \mathrm{m}$. A significant difficulty in implementing an electrically-injected device in these materials, however, is reducing the electrical resistance of the mirrors to an acceptable level. In the AlGaAsSb materials, achieving reduced resistance through compositional grading will be difficult, since lattice matching is dependent on precise compositional control.

$\mathrm{N}$-type AlAsSb/AlGaAsSb mirrors have been fabricated which exhibit resistances low enough to demonstrate that device-quality mirrors may be possible through a digital grading scheme. ${ }^{2}$ Due to larger hole effective masses and a significant valence band offset in these materials, $p$-type mirrors still have unacceptably high resistances. ${ }^{3}$ We have investigated an alternate material combination for p-type mirrors, AlAsSb/InAlGaAs, which possesses part of the enhanced refractive index contrast of the $\mathrm{AlAsSb} / \mathrm{AlGaAsSb}$ combination but has a much smaller valence band offset.

Figure 1 shows the expected band alignment of the AlAsSb/InAlGaAs combination in comparison to $\mathrm{AlAsSb} / \mathrm{AlGaAsSb}$. We have performed photoluminescence measurements on AlAsSb/InAlGaAs superlattices and observed emission only near the InAlGaAs band edge at $1.3 \mu \mathrm{m}$, indicating that the band alignment is in fact either weakly type II or perhaps even type I and should not result in excessive mirror absorption due to a long-wavelength type-II transition.

A reflectance spectrum for a 15.5-period AIAs $0.56 \mathrm{Sb}_{0.44} / \mathrm{In}_{0.53} \mathrm{Al}_{0.13} \mathrm{Ga}_{0.34} \mathrm{As}$ DBR is shown in Figure 2, along with a fit to the spectrum. From the fit, we have extracted a refractive index contrast of 0.36 for these materials, compared to a value of 0.45 from previous measurements on the AlAsSb/AlGaAsSb combination, ${ }^{3}$ and literature values of 0.3 for both $\operatorname{InAlGaAs} / \mathrm{InP}^{4}$ and GaInAsP/InP. ${ }^{5}$ A larger index contrast should be possible with a more aggressive design having an absorption edge closer to $1.55 \mu \mathrm{m}$.

Measurements of the electrical resistance of mesa-etched Be-doped p-type AlAsSb/InAlGaAs DBR structures were performed to determine the suitability of these materials for use in electrically-injected structures. The hole concentrations were estimated to be $2.6 \times 10^{18} \mathrm{~cm}^{-3}$ in the AlAsSb and $8 \times 10^{17} \mathrm{~cm}^{-3}$ in the InAlGaAs. Figure 3 shows the total resistance of the structures as a function of mesa size. Based on these measurements, a 25 -period mirror should have a total voltage drop of approximately $0.6 \mathrm{~V}$ at a current density of $1 \mathrm{kA} / \mathrm{cm}^{2}$. Due to relatively low hole mobilities in AlAsSb, we estimated that as much as one third of the total mirror resistance is due to the bulk resistance of the mirror materials. With only modest improvements, as might be expected with a simple digital grading scheme, we expect that the 
mirror resistance can be reduced sufficiently to allow incorporation of these mirrors in a low-voltage device.

This work was supported by the United States Department of Energy under Contract DE-AC0494AL85000. Sandia is a multiprogram laboratory operated by Sandia Corporation, a Lockheed Martin Company, for the United States Department of Energy.

\section{References}

1) O. Blum, J. F. Klem, K. L. Lear, G. A. Vawter, and S. R. Kurtz, Electron. Lett. 33, 1878 (1997).

2) I. N. L Dias, B. Nabet, A. Kohl, and J. C. Harmand, Electron. Lett. 33, 716 (1997).

3) O. Blum, M. J. Hafich, J. F. Klem, K. L. Lear, and S. N. G. Chu, Appl. Phys. Lett. 67, 3233 (1995).

4) A. J. Moseley, J. Thompson, D. J. Robbins, and M. Q. Kearley, Electron. Lett. 25, 1718(1989).

5) Y. Suematsu, K. Iga, and K. Kishino, in GaInAsP Alloy Semiconductors, T. P. Pearsall, ed. (Wiley, New York, 1982), p. 362.

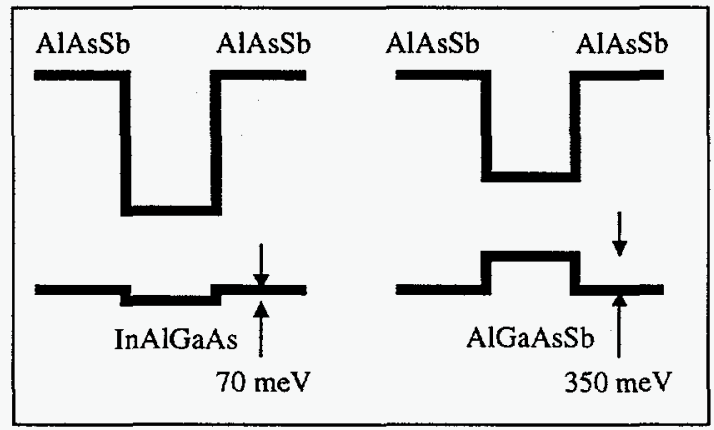

Figure 1. Estimated band alignments for AlAsSb/InAlGaAs and AlAsSb/AlGaAsSb mirrors.

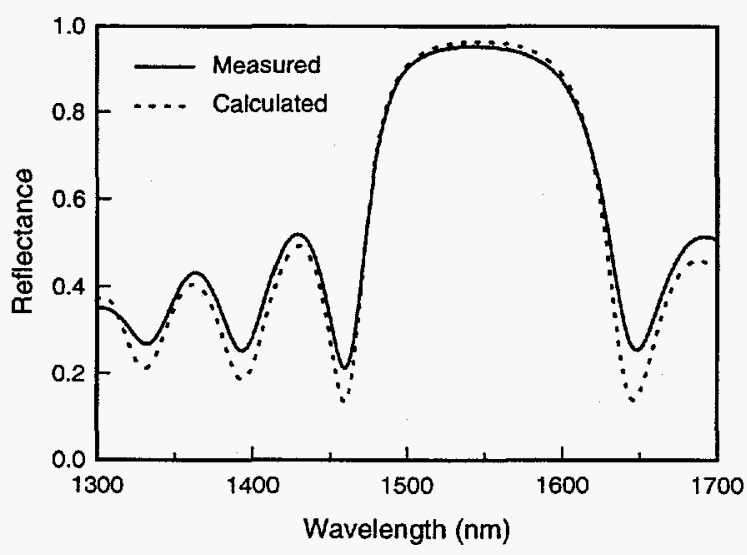

Figure 2. Reflectance spectrum of a 15.5-period AlAsSb/InAlGaAs mirror.

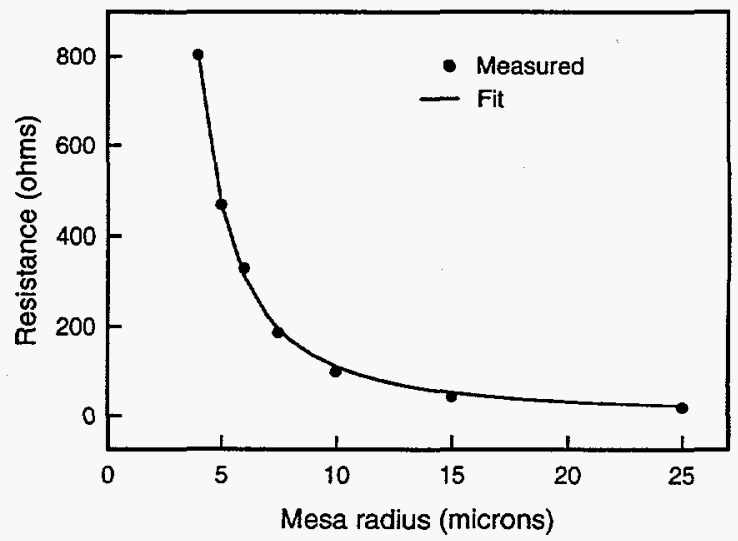

Figure 3. Resistance as a function of mesa size for a 15.5 period Be-doped $\mathrm{AlAsSb} / \mathrm{InAlGaAs}$ mirror. 